\title{
COM \\ Science on tap: effective public engagement or preaching to the choir?
}

\section{Cara Ocobock and Patricia Hawley}

\begin{abstract}
The goal of Science Cafés and Science on Taps is to encourage open discourse between scientists and the public in a casual setting (e.g., a bar) in order to improve the public understanding of, and trust in, science. These events have existed for over two decades, but there is no research studying their efficacy. Data presented here demonstrate that a yearlong Science on Tap series induced little change among the attendees with respect to attitudes, emotions, and knowledge about the nature of science. Ultimately, we found this event may be preaching to the choir rather than changing hearts and minds.
\end{abstract}

Keywords

DOI

Introduction
Public perception of science and technology; Public understanding of science and technology; Science communication: theory and models

https://doi.org/10.22323/2.19010204

Submitted: 12th August 2019

Accepted: 17th December 2019

Published: 10th February 2020
Over the last 20 years, Science Cafés [after Dallas, 1999] have become a popular medium through which to engage the community with science and scientists. The goal of such events is to encourage open scientific discourse between scientists and the public in a casual setting such as a café or a bar (often called Science on Tap when held at a bar) [Bitgood and Ahmann, 2008; Cohen and Macfarlane, 2007; Dallas, 1999; Einbinder, 2013; Norton and Nohara, 2009; Rabe, 2009]. Ideally, as an informal science learning context [e.g. Austin and Sullivan, 2019], a friendly bridge is formed between 'town and gown' to forge connections and reduce division or disinterest while improving public understanding of, trust in, and positive attitudes towards science. The casual setting and one-on-one contact would, in principle, reduce the physical and intellectual distance between scientists and the public. Furthermore, Science Cafés stand to connect scientists with diverse community members (e.g., religion, socio-economic status, political affiliation, etc), thus encouraging discourse across "the aisle" and consequently enhancing understanding and empathy for different cultural dispositions and belief systems.

But what do Science Cafés actually do? This question is vital. Recent U.S. survey data suggest that there is a considerable opinion gap between scientists and the 
general public on a number of topics in science and technology. For example, almost $90 \%$ of American Association for the Advancement of Science scientists say that genetically modified foods are safe, whereas only $37 \%$ of the general public say the same [Pew Research Center, 2015]. Furthermore, in the U.S., public understanding of basic scientific principles, particularly those pertaining to evolution and origins of the universe, lag behind other industrialized countries [National Science Board, 2018]. Contributing to this divide is the fact that the general public does not interact with science or scientists to an appreciable degree [Allum et al., 2008; Collins and Evans, 2007; Gauchat, 2011; Merton, 1973; Miller, 2004; Moore, 2008; National Science Board, 2018; Shapin, 2008]. Accordingly, there has been a vocal call within the scientific community to more effectively engage with the public to enhance knowledge, perceptions, and attitudes towards science and scientific research [Dallas, 1999; Norton and Nohara, 2009]. The hope is that these efforts generate a more scientifically literate public and electorate such that science is more highly valued in terms of funding and consultation in public policy development.

Divided opinions on the understanding the nature of and trust in science is not a new phenomenon [Gauchat, 2008; Moore, 2008; Shapin and Schaffer, 1985]. However, there is increasing evidence that this divide has deepened. Social scientists have proposed three models to explain this trend:

1. The Knowledge-Attitude Model [aka deficit model; Gauchat, 2012] posits that positive attitudes result from knowledge acquisition; that is, attitude and knowledge are positively correlated regardless of the identity features of the individual [Allum et al., 2008; Bauer, Allum and Miller, 2007; Evans and Durant, 1995; Gauchat, 2011; Hayes and Tariq, 2000; Miller, 2004]. Thus, in order to enhance public attitudes towards science, one must focus on science literacy.

2. The Meaning of Science Model explores what makes something scientific in people's minds, and thus addresses the relationship between cultural representations of science and attitudes towards it. This model suggests that cultural dispositions associated with group identity (e.g., religious affiliation) may actually trump the level of science knowledge gained from formal and informal education when it comes to attitude formation [Bauer, Petkova and Boyadjieva, 2000; Bauer, Allum and Miller, 2007; Gauchat, 2011; Gieryn, 1999; Kahan, 2015; Hawley and Sinatra, 2019]. Remediation requires sensitive acknowledgement of said identity features to help the individual resolve perceived conflicts [e.g. Hawley and Sinatra, 2019].

3. The Alienation Model suggests that disconnects between scientists and the general public, both physical (contained within universities and research institutions) and intellectual (conducted by those with advanced degrees), make science abstract and unrelatable. As a consequence, those not within scientific spheres feel alienated [Beck, 1992; Gauchat, 2011; Giddens, 1991; Habermas, 1989]. Like the Meaning of Science Model, the Alienation Model involves group identity. The focus here, however, is connection. Remediation consequently involves resolving the distance and increasing accessibility.

These models provide a useful framework for developing testable hypotheses regarding science outreach effectiveness. For example, the Knowledge-Attitude 
Model, if correct, would predict that emotions and perceptions of science would improve after a science outreach event simply because attendees would know more than before event attendance. That increase in knowledge would lead to more positive associations with science. This prediction was borne out in a 2012 study among science festival attendees [Manning et al., 2012]. Investigators found that over half of respondents reported having learned something new at a science festival and that their experiences at the festival increased their interest in science. Indeed, in another study among science expo attendees, participants rated events more positively when they personally interacted with the scientists and engineers themselves [e.g. Boyette and Ramsey, 2019].

However, the Meaning of Science and Alienation Models may provide an alternate explanation for the rather positive results of these studies. From these models, one could predict that attendees of science outreach events are those who already feel comfortable with science and ascribe to a pro-science group identity. For example, $44 \%$ of respondents attending science festivals stated that their reason for attending the event to begin with was having a general interest in science and $16 \%$ stated they attended due to a specific interest related to their profession or hobby [Manning et al., 2012]. The Meaning of Science and Alienation Models, together with data collected during science festivals indicate that these events may ultimately be preaching to the choir: those who attend science outreach events are already interested in and positively inclined towards science. In today's sociopolitical climate, these latter two models suggest that identities characterized by high levels of religiosity and conservatism view science less favorably [Gauchat, 2012]. Indeed, it is well documented that scientists are less religious than the public [Pew Research Center, 2009] and, for example, there are deep political divisions as to whether climate change is due to human activity [Funk and Kennedy, 2009; but see Carl, Cofnas and Menie, 2016].

Public outreach institutions, activities and events have long played an important role in community education [e.g. Goode, 1889]. The present work is focused on the modern so-named Science Cafes or Science on Taps which typically involve a community speaker series at a coffee house or bar. Much of the work conducted on Science Cafés and Science on Taps focuses on how to best develop an event [Bitgood and Ahmann, 2008; Cohen and Macfarlane, 2007; Rabe, 2009], draw large audiences [Bitgood and Ahmann, 2008], and track event success in terms of marketing (attendance) and participant satisfaction [Bitgood and Ahmann, 2008; Einbinder, 2013; Johnson, 2014]. Critically, though these types of events have been around for more than two decades, to our knowledge, there is currently no research studying their efficacy on improving public understanding or perception of science. Through the present work, we attempt to redress this gap.

Thus, important questions remain: do Science Cafés and Science on Taps have a measurable effect on the public's view of science? Namely, who attends these events? Are the events attractive only to people with knowledge about science, pro-science identities or attitudes, and feel comfortable in scientific spheres? Or, do the friendly and informal atmospheres of Science Cafés and Science on Taps successfully reach those who are less knowledgeable about science and are skeptical towards science and scientists? Moreover, can these events claim success in changing attitudes for the better? 


\section{Goals and hypotheses}

The goal of the present study is to explore the effects of a Science on Tap series on public attitudes (e.g., trust), emotions [e.g., anxiety and enthusiasm; Pekrun and Perry, 2014], and knowledge about the nature of science, and how attitudes, emotions, and knowledge are associated with group identity variables such as religiosity and political self-identity. We hypothesized that, according to the Alienation and Meaning of Science Models, which have similar underpinnings, that Science on Tap attendees would, on the whole, already be closely connected to scientific fields and identify as pro-science (e.g., high trust and positive attitudes). We also hypothesized that a conservative and religious self-identity would obstruct positive attitudes. If these two hypotheses bear out, outreach efforts like Science on Tap would not be particularly useful for bolstering trust in science and scientists as the audience, due to self-identification, already has a great deal of trust in science. Finally, following the Knowledge-Attitude Model, we hypothesized that Science on Tap attendance would improve scientific knowledge and thereby improve the already high positive attitudes towards science. In essence, we expect elements of each of the models to be reflected in our measured outcomes.

To test these hypotheses and determine the outreach efficacy of this particular Science on Tap, we collected pre- and post-event survey data on attitudes, emotions, and knowledge about the nature of science, as well as measures of religiosity, political self-identity, and basic demographics among attendees across ten Science on Tap events in the Capital Region of New York.

\section{Methods}

Science on Tap Capital Region (spanning the New York cities of Albany, Schenectady, and Troy) was founded in February of 2017 by the first author. Ten events were held on a monthly basis rotating among local bars in each of the three cities. Events consisted of one or a panel of experts to speak to their expertise through a 30-40 minute talk followed by a question and answer session which lasted a similar amount of time. Data were collected by the first author (CO) during each of these events. This study was reviewed by and received exempt status from the University at Albany Institutional Review Board (reference number: 17-X-097-01).

\section{Participants}

Participants were individuals who either knew the event was happening (i.e., through local advertising via Facebook and email), or individuals who were at the bar when the event took place and decided to join.

\section{Survey design}

The present study utilized a pre-event/post-event survey design. Pre-event surveys were handed out to event attendees before the presentation began. The first author and organizer of the events provided oral instructions on filling out the survey and collected completed surveys within 10 minutes after the event started. With roughly 5 minutes left in the event, post-event surveys were distributed and 
explained. Participants handed in their surveys to $\mathrm{CO}$ as they left the bar. The surveys were kept as brief as possible given the nature of the event and the constraints of the setting.

Pre-event instructions. Participants were asked to create a codename so that their responses could be tracked across events. "FIRST: please create a codename so that your surveys can be matched. So that you will remember, let's use the first 2 letters of your father's name, followed by the first 2 letters of your mother's, followed by a year you will remember. For example, my father was William, my mother was Rachael, my first child was born in 2010. >> WiRa10").

Post-event instructions. Participants were asked to match their pre-event codename to the best of their recollection.

Pre-event and post-event surveys were matched according to codename. Across events, codenames were carefully examined for repeats (or near repeats) in order to cull multiple records within individual participants. When participants attended multiple events, data from their first event were used in order to avoid practice effects.

\section{Measures}

Basic demographics. The respondents in this sample identified as either male or female, with male being coded as one and female coded as zero. We asked them also to identify their age, occupation, student status, and whether they identify themselves as working in a scientific field broadly defined.

Religiosity. Religiosity is a powerful predictor of trust in science and scientists [e.g. Evans, 2011; Johnson, Scheitle and Ecklund, 2015]. We measured religiosity by way of two highly correlated items $(\alpha=.93)$ : What is your level of religious commitment? (" 1 " = none at all; " 5 " = very high); How important is your religion to you ["1" = not at all; " 5 " = very; cf. Hawley, Short et al., 2011]. High scores denote high religiosity. Religiosity was measured once, post-event.

Political self-identity. Political ideation is a powerful predictor of attitudes towards scientific concepts and approaches [e.g. Miller, Scott and Okamoto, 2006]. Participants responded to a single scale: In general, how do you self-identify politically? [measured on a 7 point scale; " 1 " = strong democrat, "7" = strong republican; Hawley, Short et al., 2011]. Higher scores indicate a higher level of conservatism. Political self-identity was measured once, post-event.

Attitudes (e.g., trust). Pre- and post-event, three items were used to assess trust of science [Nadelson et al., 2014]: We should trust the work of scientists; Scientific theories are trustworthy; and We can trust science to find the answers that explain the natural world. The items demonstrated sufficient internal consistency to warrant collapsing into a single scale (pre-event: $\alpha=.67$; post-event: $\alpha=.75$ ). 
Knowledge of the nature of science (NOS). Three items were drawn from the Nature of Science Scale [NOS: Lombrozo, Thanukos and Weisberg, 2008]: Scientific knowledge is tentative (NOS Item 1); Science involves only things that can be seen directly (reverse coded) (NOS Item 2); Scientific theories are hunches (reverse coded) (NOS Item 3). Rather than being knowledge kernels about the scientific process per se (e.g., data collection, interpretation) - which differed greatly across the events - understanding the nature of science concerns more the epistemological assumptions and values that underlie the activity of the scientific enterprise [Lederman et al., 2002]. The items did not have a sufficient internal consistency to warrant collapsing into one subscale and thus are kept separate (i.e., $\alpha=.07$ ).

Emotions. Three negative emotions (When I think about science, I feel. . a anxious, conflicted, reluctance) and three positive emotions (When I think about science, I feel... enthusiastic, happy, curious) were assessed via two items administered both before and after the event [after Pekrun and Perry, 2014; Hawley and Sinatra, 2019]. Participants responded on a five point scale (" 1 " = strongly disagree; " 5 " = strongly agree).

Perceptions of enjoyment and learning: value. Finally, participants were asked the degree to which a) they learned something new, b) enjoyed the presentation, and c) changed their mind about something as a consequence of the event, all measured on a 7-point scale (high scores indicate high learning and enjoyment). The items demonstrated sufficient internal consistency to warrant collapsing into a single scale (post-event: $\alpha=.59$ ) which we will refer to as Value (i.e., perceptions of the value of the experience).

\section{Pre/post retrospective design}

The post-event items were presented in the following form: Before the workshop, when I thought about science I felt... anxious, conflicted, reluctance; Before the workshop, when I thought about science I felt... enthusiastic, happy, curious; After the workshop when I think about science I feel... anxious, conflicted, reluctance; After the workshop when I think about science I feel... enthusiastic, happy, curious. This pre-post retrospective design was used in order to explore response shift effects (a threat to validity) inherent to simple pre-/post-test designs [see Hawley and Sinatra, 2019, for extended discussion]. The pre-event items described above are referred to as "pretest" items. The post-event items are referred to as "thentest" items (Before the workshop, when I thought about science I felt...) and "posttest" items (After the workshop when I think about science I feel...). The difference between the pretest and the thentest represents a response-shift after exposure, leading some to argue that the difference between the thentest and posttest is consequently a better estimate of the treatment effect [Finkelstein, Quaranto and Schwartz, 2014], especially for events where one wishes to capture participants' evaluations about the effectiveness of the curriculum [Lamb, 2005]. 
Demographics and identity features. Overall, 327 pre-event surveys and 319 post-event surveys were completed, which reflect most accurately one measure of success: the overall attendance to the series. Importantly, many respondents attended multiple events. For the purpose of the present study, 'participants' were a) limited to those with an identifiable codename, and b) limited to a single attendance (the participant's first) to avoid dependencies in the dataset. After culling for missing identifiers and participant dependencies, there were 251 unique survey respondents over the course of ten Science on Tap events who completed pre-event and post-event surveys. Their average age from the final sample was 37.19 years $(S=13.58), 146$ identified as female, 105 identified as male, 77 were students, 164 were non-students $(62.8 \%$ of which identified being in a scientific field). In the end, $72.5 \%$ of the sample identified with a science field. Alcohol was being purchased, but participant drinking behaviors were neither monitored nor recorded.

\section{Gender differences and similarities}

Religiosity and conservatism. Religiosity and conservatism were compared between male and female participants. Descriptive statistics can be found in Table 1. As seen in Table 1, men and women did not differ in terms of Religiosity, but the men in the sample rated themselves as more conservative than the women $\operatorname{did}(\mathrm{p}<.0001)$.

Table 1. Mean comparisons between female and male attendees.

\begin{tabular}{|lccc|}
\hline & Women $(n=141)$ & Men $(n=100)$ & $p$ \\
\hline Religiosity & $1.99(1.18)$ & $1.75(1.13)$ & 0.17 \\
Conservatism & $2.26(1.22)$ & $2.96(1.33)$ & $<.0001$ \\
Trust & $6.24(0.74)$ & $5.91(0.88)$ & $\mathrm{F}_{1,218}=9.85 ; \mathrm{p}=.0019$ \\
Negative Emotions & $1.45(0.73)$ & $1.62(0.96)$ & 0.17 \\
Positive Emotions & $4.74(0.62)$ & $4.67(0.75)$ & 0.59 \\
NOS 1 & $3.95(1.79)$ & $4.31(1.81)$ & 0.11 \\
NOS 2 & $6.01(1.38)$ & $6.21(1.31)$ & 0.18 \\
NOS 3 & $6.13(1.27)$ & $5.95(1.44)$ & 0.47 \\
Value & $5.48(0.94)$ & $5.31(0.90)$ & 0.22 \\
\hline
\end{tabular}

Note: NOS 1: Scientific knowledge is tentative; NOS 2: Science involves only things that can be seen directly (reverse coded); NOS 3: Scientific theories are hunches (reverse coded). Conservative self-identity did not exceed 3.0 for either men or women. The national average on a 7 point scale of political ideation is 4.125 [Pew Research Center, 2014].

Trust in science, emotions, knowledge, and value. As seen in Table 1, women reported themselves as trusting science more so than men, but there were no statistically significant gender differences in Negative Emotions, Positive Emotions, the three NOS items, or finding value in the event. 
Conservatism and religiosity. Religiosity was compared between those who reported working or studying in a science field and those who did not. Descriptive statistics can be found in Table 2. As seen in Table 2, scientists and non-scientists did not differ in terms of Religiosity or Conservatism.

Table 2. Mean differences between scientists and those not affiliated with a science field.

\begin{tabular}{|c|c|c|c|}
\hline & Science $(n=174)$ & Non-Science $(n=66)$ & \\
\hline Religiosity & $1.89(1.14)$ & $1.96(1.31)$ & $\mathrm{p}=.70$ \\
\hline Conservatism & $2.57(1.36)$ & $2.46(1.16)$ & $p=.62$ \\
\hline Trust & $6.19(0.73)$ & $5.86(0.93)$ & $\mathrm{F}_{1,239}=16.74 ; \mathrm{p}=.0065$ \\
\hline Negative Emotions & $1.43(0.77)$ & $1.78(0.95)$ & $F_{1,239}=7.08 ; p=.0083$ \\
\hline Positive Emotions & $4.81(0.60)$ & $4.44(0.79)$ & $\mathrm{F}_{1,239}=13.01 ; \mathrm{p}=.0004$ \\
\hline NOS 1 & $4.21(1.80)$ & $3.81(1.81)$ & $\mathrm{p}=.14$ \\
\hline NOS 2 & $6.06(1.35)$ & $6.18(1.37)$ & $\mathrm{p}=.05$ \\
\hline NOS 3 & $6.18(1.25)$ & $5.71(1.42)$ & $\mathrm{F}_{1,239}=5.93 ; \mathrm{p}=.0156$ \\
\hline Value & $5.39(0.93)$ & $5.46(0.93)$ & $\mathrm{p}=.62$ \\
\hline
\end{tabular}

Note: NOS 1: Scientific knowledge is tentative; NOS 2: Science involves only things that can be seen directly (reverse coded); NOS 3: Scientific theories are hunches (reverse coded). Both scientists and non-scientists scored well below the national average of 4.125 on conservatism [Kiley and Keeter, 2015].

Trust in science, emotions, knowledge, and value. As seen in Table 2, those involved in scientific endeavors reported significantly higher levels of Trust, significantly lower levels of Negative Emotions, significantly higher levels of Positive Emotions, and scored significantly better on NOS 3 (Scientific theories are hunches, reverse coded). Interestingly, scientists scored more poorly on NOS 2 (Science involves only things that can be seen directly, reverse coded). Because this item was reverse coded, it favors answers that consider the role of inference, an indirect way of drawing conclusions (e.g., the speed of light cannot be seen directly). Scientists and non-scientists did not differ in finding value in the event.

\section{Responses to events}

As seen in Table 3, participant ratings for Trust in science and scores on the NOS items did not change pre- and post-event except for scores on NOS 3 (Scientific theories are hunches, reverse coded), which decreased over time (which here means that after the event, participants were more likely to align theories with mere hunches). Furthermore, there were no significant differences in Negative or Positive Emotions either between pretest and posttest, or reflective post-event thentest and posttest. Last, we conducted a post hoc analysis to see if any event 'stood out' as affecting change. None did. Event by event results mirrored the overall pattern below.

\section{Correlations}

Because the greatest differences occurred between scientists and non-scientists, we performed our correlations by science status for comparison (see Table 4). 
Table 3. Changes in trust, knowledge of science items, and emotions before and after Science on Tap events.

\begin{tabular}{|lcccc|}
\hline & $\begin{array}{c}\text { Pre-event } \\
\text { "pretest" }\end{array}$ & $\begin{array}{c}\text { Reflective Post-event } \\
\text { "thentest" }\end{array}$ & $\begin{array}{c}\text { Post-event } \\
\text { "posttest" }\end{array}$ & $p$ \\
\hline Trust & $6.09(0.79)$ & na & $6.11(0.83)$ & 0.59 \\
NOS 1 & $4.08(1.81)$ & na & $4.04(1.83)$ & 0.53 \\
NOS 2 & $6.09(1.33)$ & na & $6.02(1.38)$ & 0.18 \\
NOS 3 & $6.00(1.38)$ & na & $5.81(1.53)$ & $\mathrm{t}_{249}=2.73 ; \mathrm{p}=.007$ \\
Negative Emotions & $1.52(0.83)$ & $1.50(0.83)$ & $1.53(0.92)$ & 0.48 \\
Positive Emotions & $4.70(0.68)$ & $4.66(0.61)$ & $4.66(0.63)$ & 0.99 \\
\hline
\end{tabular}

Note: NOS 1: Scientific knowledge is tentative; NOS 2: Science involves only things that can be seen directly (reverse coded); NOS 3: Scientific theories are hunches (reverse coded). Null results remained after controlling for Religiosity and Conservatism. Responses to workshop did not vary by scientist and non-scientist status.

Table 4. Inter-variable correlations for scientists and non-scientists.

\begin{tabular}{|c|c|c|c|c|c|c|c|c|c|c|}
\hline \multicolumn{11}{|c|}{ Respondents in Science Fields } \\
\hline & Age & Relig. & Conserv. & Trust & NOS 1 & NOS 2 & NOS 3 & Neg. & Pos. & Value \\
\hline Age & $x$ & & & & & & & & & \\
\hline Religiosity & -.06 & $x$ & & & & & & & & \\
\hline Conservatism & -.15 & $.33^{* *}$ & $x$ & & & & & & & \\
\hline Trust & -.06 & $-.28^{* *}$ & $-.29^{* *}$ & $x$ & & & & & & \\
\hline NOS 1 & -.14 & -.11 & .04 & -.09 & $x$ & & & & & \\
\hline NOS 2 & -.02 & .04 & -.10 & .14 & .00 & $x$ & & & & \\
\hline NOS 3 & -.19 & -.08 & -.17 & $.27^{* *}$ & -.05 & .11 & $x$ & & & \\
\hline Negative Emotions & -.07 & .07 & -.03 & -.12 & .09 & .11 & .04 & $\mathrm{x}$ & & \\
\hline Positive Emotions & -.17 & .01 & .07 & .13 & .02 & -.02 & .05 & $-.24^{* *}$ & $x$ & \\
\hline Value & -.05 & .13 & -.06 & .07 & .04 & .00 & .12 & -.04 & .05 & $x$ \\
\hline
\end{tabular}

\begin{tabular}{|c|c|c|c|c|c|c|c|c|c|c|}
\hline \multicolumn{11}{|c|}{ Respondents in Non-Science Fields } \\
\hline & Age & Relig. & Conserv. & Trust & NOS 1 & NOS 2 & NOS 3 & Neg. & Pos. & Value \\
\hline Age & $x$ & & & & & & & & & \\
\hline Religiosity & .00 & $x$ & & & & & & & & \\
\hline Conservatism & $-.39 * *$ & -.09 & $x$ & & & & & & & \\
\hline Trust & -.01 & -.20 & $-.44^{* *}$ & $x$ & & & & & & \\
\hline NOS 1 & $-.34^{* *}$ & -.04 & .21 & -.11 & $x$ & & & & & \\
\hline NOS 2 & .07 & -.18 & -.06 & .14 & -.03 & $x$ & & & & \\
\hline NOS 3 & $.27^{*}$ & -.16 & -.16 & $.28^{*}$ & $-.47^{* *}$ & $.31^{*}$ & $x$ & & & \\
\hline Negative Emotions & -.20 & .00 & .10 & $-.32^{* *}$ & .22 & $-.42^{* *}$ & $-.26^{*}$ & $x$ & & \\
\hline Positive Emotions & -.03 & $-.26^{*}$ & -.23 & $.28^{*}$ & -.16 & $.37^{* *}$ & $.32^{*}$ & $-.41^{* *}$ & $x$ & \\
\hline Value & -.18 & .09 & .00 & $.28^{*}$ & -.11 & .09 & .01 & -.03 & -.07 & $x$ \\
\hline
\end{tabular}

Note: Correlations for those in science fields (top matrix, $\mathrm{n}=173, *<.01^{* *}<.001$ ) and those in non-science fields (bottom matrix, $\mathrm{n}=66,{ }^{*}=<.05^{* *}<.01$ ) for group identity, trust in science, knowledge of science items (NOS 1: Scientific knowledge is tentative; NOS 2: Science involves only things that can be seen directly (reverse coded); NOS 3: Scientific theories are hunches (reverse coded)), emotions towards science, and level of value found in the event.

Identity variables. As seen in Table 4, Age and Conservatism were negatively related in non-scientific Science on Tap attendees, and Conservatism and 
Religiosity were positively related in scientific attendees $(\mathrm{r}=-.28 ; \mathrm{p}<.001)$. This relationship did not hold for non-scientific attendees (though, the correlations of -.20 in non-scientists is not significantly different from the -.28 in scientists). Also, Conservatism and Religiosity were positively correlated in scientists only $(\mathrm{r}=.33$; $\mathrm{p}<.001$ ). Positive emotions and Negative emotions were significantly negatively correlated in both, as would be expected through validity lenses.

Trust. We found that Conservatism and Religiosity were negatively related to Trust: the more conservative and/or religious the attendee, the less trusting s/he was of science. A similar pattern was found in non-scientists: while Conservatism was strongly correlated with Trust $(\mathrm{r}=-.44 ; \mathrm{p}<.001)$, the negative correlation with Religiosity did not achieve significance $(r=-.20 ; p>.05)$. In both scientists and non-scientists, Trust was positively associated with knowing that theories are not hunches $(\mathrm{r}=.27 ; \mathrm{p}<.001)$.

Nature of science. The Nature of Science items were not consistently positively intercorrelated. In scientists, they were not correlated at all. NOS 2 and 3, however, positively correlated in non-scientists $(\mathrm{r}=.31 ; \mathrm{p}<.05)$ : the more respondents understood that evidence need not be seen directly (i.e., they presumably understood the role of inference), the more they understood theories were not hunches. Interestingly, the more they understood these two concepts), the more positively (NOS 2: $\mathrm{r}=.37 ; \mathrm{p}<.01 ; \mathrm{NOS} 3 ; \mathrm{r}=.32 ; \mathrm{p}<.05$ ) - and less negatively (NOS 2: $r=-.42 ; p<.01 ;$ NOS 3; $r=-.26 ; p<.05)$ - they felt about science.

Finding value in the event. The only correlation to perceptions of Value and 'having learned something' was Trust in non-scientific participants $(r=.28 ; \mathrm{p}<.05)$

This study assessed the effects of a Science on Tap series over the course of nearly a year on public perceptions and understanding of the nature of science as well as how audience demographics related to perception and understanding. Specifically, this study tested two main hypotheses: 1) following the Alienation and Meaning of Science models, prior to Science on Tap events, attendees will already be connected to scientific fields and self-identify pro-science, and 2) following the

Knowledge-Attitude model, Science on Tap will improve scientific knowledge and attitudes towards science among event attendees. To the authors' knowledge, this is the first published study to determine who is attending Science on Tap style events and to assess the efficacy of this form of science outreach.

\section{Attendees}

Event participants were largely from science fields (72.5\% across the sample) and most were non-students $(65.3 \%)$, which indicates what many Science on Tap and Science Café organizers have long suspected and confirming our first hypothesis, that those attending events are those who are already interested in and trust science.

Moreover, the sample scored well below the national average on Conservatism, and well below the samples from Kansas [M = 3.75; Hawley, Short et al., 2011] and 
West Texas [M = 5.35; Hawley and Sinatra, 2019] on a religiosity measure from which the present one was derived. This is not surprising as in New York, 29\% of people identify as conservative while $65 \%$ identify as moderate or liberal [Pew Research Center, 2014]. Recent work in motivated cognition and psychological approaches to science education have turned their attention to what the National Academy of Sciences has referred to as "noncognitive factors" [National Research Council, 2012] such as beliefs, identity, and motivations [Hawley and Sinatra, 2019; Kahan, 2015; Kahan, Jenkins-Smith and Braman, 2011; Sinatra and Seyranian, 2016]. Much of this work is ultimately derived from sociological models of the relationships of subgroups to societal institutions such as science. For example, the last several decades have seen conservative ideation (and the correlated religiosity) become increasingly associated with mistrust of science [Gauchat, 2012], and one would accordingly expect that this identity feature would be associated with unfavorable views towards Science Cafes and Science on Taps. Indeed, we saw evidence for this expectation reflected in our attendee pool which identified predominantly as liberal and non-religious. This finding lends credence to the Meaning of Science and Alienation models.

Interestingly, although Age and Conservatism are associated in the population in the U.S., with Baby Boomers being more conservative than Millennials [Kiley and Keeter, 2015; Maniam and Smith, 2017], our sample of Science on Tap attendees showed a significantly negative correlation between Age and Conservatism in non-scientists (and trending in scientists). We interpret this to mean that older conservatives simply did not attend the science events. This result reflects the predictions put forth by both the Meaning of Science and Alienation models as the purpose of Science on Tap does not align with their group identity views on science, dissuading attendance. These results mirror those assessing the demographics and attitudes towards science among science festival attendees who are more science literate than the population as a whole. Accordingly, science festival attendees' evaluations of such events are largely favorable [Canovan, 2019]. This finding suggests that neither this style of event, nor science festivals, is attracting the target demographic: those with less trust in and high negative emotions towards science - the very demographic whose views these events are often meant to influence.

\section{Trust and emotions}

The correlations. At the same time, within scientists as well as non-scientists, Conservatism was significantly negatively associated with Trust, and, to a lesser degree, Religiosity. At first glance these correlations within academia may be surprising. However, when one considers that the post-modernist movement which questions the objectivity of science and the 'factuality' of its claims was born in the halls of higher education [Gauchat, 2012; Kuntz, 2012], this pattern makes a good deal of sense. The tentative and interpretative nature of science may thus sow distrust. Such a view may even give rise to an 'anything goes' attitude towards scientific theories. From a science standpoint, theories are testable and tested explanatory frameworks. From a post-modernist perspective, theories may be highly subjective and susceptible to time and place. From this latter view, it is easy to slip into a 'theories are hunches' orientation, which would understandably sow mistrust. Apropos to this point, both for scientists and non-scientists alike, Trust 
was significantly correlated with our Nature of Science item aligning theories with hunches; namely, those who understood the difference between theories and hunches had greater trust in science. It is possible that the public picks up on these cues from the scientific community, particularly in the age where scientific theories are presented and debated on social media platforms for the world to see. Though such transparency has myriad benefits, it could also fuel the perception that unless there is $100 \%$ agreement within the scientific community, a theory cannot be "trusted".

The means. Measures of trust in, knowledge about the nature of, and emotions towards science revealed interesting mean differences between scientists and non-scientists. There was no difference in knowledge about the nature of science between these two groups, at least on the items we chose to represent the nature of science (see also Limitations). However, those from science fields had greater trust in and more positive emotions towards science than their non-science field counterparts. These results suggest that the Knowledge-Attitude Model may not apply in this sample as knowledge about the nature of science did not reveal a gap in understanding between science and non-science participants as reflected in our nature of science items. Furthermore, the negative correlation between trust in and negative emotions towards science among non-scientists (see above) suggests that the Meaning of Science model may be more representative of larger patterns in attitudes towards science. These two findings allow us to reject our second hypothesis [Bauer, Petkova and Boyadjieva, 2000; Bauer, Allum and Miller, 2007; Gauchat, 2011; Gieryn, 1999; Kahan, 2015; Hawley and Sinatra, 2019].

\section{Nature of science}

Though targeting specific gaps is not an advisable approach to improving knowledge of and trust in science, addressing the nature of theories and their role in the scientific process may be a critical concept to clarify for the public. We found a significant pre-post difference on NOS 3, which examined whether participants viewed scientific theories as mere hunches rather than well-established and well supported explanations of observable phenomena [Suppe, 1977; Lederman et al., 2002]. Our results indicate that after Science on Tap events, participants were more likely to align theories with hunches - which is in direct opposition to the goals of science outreach events.

At first glance, this result seems puzzling. We can think of four possible explanations. First, after hearing the talk, participants may have experienced some confusion about the role of theory because of either presentation style or unfamiliarity with the content. Sometimes in scientific talks, hypotheses are confused with theories. The tentativeness of the hypotheses may have been confused with "hunchiness" in the word "theory". Or, presenters may not have presented a formal theoretical framework at all. Second, some scientific misconceptions are 'stickier' than others, and some scientific content even inadvertently increases misconceptions [e.g. Short and Hawley, 2015]. Educational work on knowledge about the nature of science has shown, for example, that beliefs that theories are hunches are persistent even after instruction [Concannon, Brown and Brown, 2013]. Third, science education researchers by and large are of the well-informed opinion that understanding the nature of science requires sustained 
explicit instruction, with inquiry-based and reflective pedagogical practices [Akerson, Abd-El-Khalick and Lederman, 2000; Concannon, Brown and Brown, 2013]. These practices are not (and probably should not be) incorporated into community science events. This latter point raises an interesting question: what are the knowledge goals of Science on Taps and Science Cafés, and how should they be measured? Fourth, scientists deal in and are comfortable with uncertainty, as it drives scientific inquiry [Schneider, 2010; Stocking and Holstein, 2009]. However, it was recently found that science journalists, the frequent mediators between scientists and the public, rarely report on scientific uncertainty in their work as a result of how they believe their audience may perceive uncertainty [Guenther and Ruhrmann, 2016]. This may mean that when scientists present their work and the uncertainties associated with the grounding theory of their research in events like Science on Tap, it is likely the first time the general public is hearing about such uncertainty. This may lead audience members to call into question their previously held beliefs on the difference between theories and hunches.

\section{Recommendations}

The results of this study suggest that Science on Tap, and by extension Science Cafés, are unknowingly reaching an audience that already has a positive view of science and scientists. Though this may not be the intended audience or goal of this type of outreach event, that does not mean one should throw the baby out with the bath water. Science on Tap still connects scientists with the community and provides a time and place for the public to become aware of the kind of work being done locally and globally. However, there is a great deal of room for improvement, as such we have four primary recommendations to move science outreach efforts forward:

1. Embrace Uncertainty: scientists and science communicators need to be more upfront and clear about the difference between a theory and a hunch. It would also be beneficial for scientists conducting outreach and working with science journalists to comment on uncertainty. Scientists and science journalists need to take greater care in expressing how uncertainty works within science and propels scientific innovation, or perhaps framing uncertainties more as questions to be answered rather than just "We don't know."

2. Make a Personal Connection: in order to address declining public opinions of science and scientists, public outreach efforts need not focus on gaps in knowledge per se (which are notoriously difficult to target, see Limitations), but rather focus on making deeper, more personal connections between scientists and the public. Attempts to adjust attitudes towards science may optimally be possible through a connection on an emotional level that presents the impact of science on relatable, everyday life. Such efforts are underway with the successful Two Scientists Walk Into a Bar $\AA$ event in San Diego, CA. During this minimally advertised event, scientists pair off and go to happy hours across the San Diego area and strike up casual conversations about science with other bar patrons. Given the spontaneous nature of this event, the self-selected audience observed at Science on Taps in this study is avoided. This provides an opportunity to reach members of the public less inclined to attended science outreach event. 
3. Hone Communication Skills: the only way for recommendations \#1 and \#2 above to be successful is for the participating scientists to be practiced communicators. Explaining one's work to the public in any venue is not the same as explaining one's work at a national conference, and, unfortunately, academic training often undervalues good general public communication skills. Providing science communication training that emphasizes connecting with the audience, eliminating jargon, and building active listening will better prepare scientists for not only structured events like Science on Tap, but also for any conversation they may find themselves in with non-scientists.

4. Know Your Audience and Know Your Goal: the most important point to come from this study is that there is a dire need to assess current outreach efforts. For example, after discussing the results of this study, Science on Tap organizers from the Capital Region of New York started to include greater science communication training as well as implement Two Scientists Walk Into a Bar $($. By doing so, they keep Science on Tap and provide a space for members of the public to learn about new advances and connect with local scientists; however, they also added new efforts to reach a broader audience and improve the way scientists communicate. As such, we recommend Science Café/on Tap organizers conduct similar survey-based studies with their respective audiences. Such work would help each organizer(s) better understand who their audience is and if they are reaching their intended goal. Furthermore, it would provide guidance on how to expand existing efforts, and in which ways current efforts might be improved upon to more effectively reach a broader audience.

\section{Limitations}

There were a number of limitations to this study. One potential confounding factor was alcohol consumption during events. These events did take place in bars, and many attendees did imbibe. How this may have impacted questionnaire response is unclear. In future studies a question asking for the number of drinks consumed should be included. This study was also limited to the Capital Region of New York, and as such, likely not representative of different geographic regions or the country as a whole. The design of this particular Science on Tap was more akin to a public lecture. There is a growing body of evidence suggesting that such a style is not conducive to learning, and other events with a more interactive nature may be more successful at changing trust in and attitudes towards science among non-scientists [e.g. Martin et al., 2016]. Our Knowledge of Science questions were concerned with the nature of science in general, and were not specific to the topic of each event. As such, they were not specifically addressed by the presenters. Thus, hoping for change after exposure to specific content is rather untenable. It is possible the results would have revealed greater increases in knowledge if questions were geared towards the specific topic discussed during each event. In this study there was a lack of anonymity during data collection in that the questionnaires were filled out at each attendee's seat in very close proximity to other attendees. It is possible that "over the shoulder" glances may have pressured participants to answer the questionnaire differently than if they were in a private setting. Finally, our sample size for non-scientists was rather small (though not prohibitively so). 


\section{Conclusions}

The results of this study suggest Science on Tap is not working in the way we would like. First, Science on Tap is not succeeding in clarifying the important difference between scientific theories and mere hunches. This finding highlights the need for scientists and science journalists to reframe how they present theories to the general public, as the public has a different perception about the implications of uncertainty than the scientific community. Second, Science on Tap, like other science events, appears to be preaching to the choir - the minds and attitudes that are attending are not the minds and attitudes we hope to change. However, despite these seemingly disheartening results and aforementioned limitations, Science on Tap still has an important role, connecting scientists to the public and providing opportunities for interested parties to learn more about the science being conducted in their very own communities. This may likely increase scientific literacy even though it may be within the narrow scope of each event's topic. The economic, personal, political, and cultural rationales for increasing scientific literacy are well documented elsewhere [National Academies of Sciences, Engineering and Medicine, 2016] and are powerful arguments for continuing with such efforts as Science on Tap. Most importantly, this study highlights the need to be cognizant that not all forms of science outreach are effective in the ways we intend. As a scientific community we need to better assess the goals, implementation, and outcomes of our science outreach efforts to broaden our audience and impact. were patient with and open to data collection during their talks. We would also like to thank Aaron Fram for editing the final draft of this manuscript.

References

Akerson, V. L., Abd-El-Khalick, F. and Lederman, N. G. (2000). 'Influence of a reflective explicit activity-based approach on elementary teachers' conceptions of nature of science'. Journal of Research in Science Teaching 37 (4), pp. 295-317. https://doi.org/10.1002/(sici) 1098-2736(200004)37:4<295: :aid-tea2>3 . 0. co;2-2.

Allum, N., Sturgis, P., Tabourazi, D. and Brunton-Smith, I. (2008). 'Science knowledge and attitudes across cultures: a meta-analysis'. Public Understanding of Science 17 (1), pp. 35-54. https: //doi .org/10 .1177/0963662506070159.

Austin, S. R. P. and Sullivan, M. (2019). 'How are we performing? Evidence for the value of science shows'. International Journal of Science Education, Part B 9 (1), pp. 1-12. https://doi.org/10.1080/21548455.2018.1532620.

Bauer, M. W., Allum, N. and Miller, S. (2007). 'What can we learn from 25 years of PUS survey research? Liberating and expanding the agenda'. Public Understanding of Science 16 (1), pp. 79-95. https://doi.org/10.1177/0963662506071287.

Bauer, M. W., Petkova, K. and Boyadjieva, P. (2000). ‘Public knowledge of and attitudes to science: alternative measures that may end the "science war"'. Science, Technology, \& Human Values 25 (1), pp. 30-51. https://doi.org/10.1177/016224390002500102.

Beck, U. (1992). Risk Society: Towards a New Modernity. First published in German, 1986. London, U.K.: SAGE Publications. 
Bitgood, S. and Ahmann, K. (2008). 'Science Café: lessons from two years of evaluation'. Informal Learning Review 91, pp. 8-11.

Boyette, T. and Ramsey, J. (2019). 'Does the messenger matter? Studying the impacts of scientists and engineers interacting with public audiences at science festival events'. JCOM 18 (02), A02. https://doi .org/10.22323/2.18020202.

Canovan, C. (2019). "“Going to these events truly opens your eyes". Perceptions of science and science careers following a family visit to a science festival'. JCOM 18 (02), A01. https://doi.org/10.22323/2.18020201.

Carl, N., Cofnas, N. and Menie, M. A. W. (2016). 'Scientific literacy, optimism about science and conservatism'. Personality and Individual Differences 94, pp. 299-302. https://doi.org/10.1016/j.paid.2016.01.046.

Cohen, J. and Macfarlane, H. (2007). 'Beer and bosons at the Café Scientifique'. Museums \& Social Issues 2 (2), pp. 233-242. https://doi.org/10.1179/msi.2007.2.2.233.

Collins, H. M. and Evans, R. (2007). Rethinking expertise. Chicago, U.S.A. and London, U.K.: University of Chicago Press.

Concannon, J. P., Brown, P. L. and Brown, E. (2013). 'Prospective teachers' perceptions of science theories: an action research study'. Creative Education 04 (01), pp. 82-88. https://doi.org/10.4236/ce.2013.41011.

Dallas, D. (1999). 'The Café Scientifique'. Nature 399 (6732), pp. 120-120. https://doi.org/10.1038/20118.

Einbinder, A. (2013). 'Understanding the popular Science Café experience using the excellent judges framework'. Informal Learning Review 6, pp. 6-10.

Evans, G. and Durant, J. (1995). 'The relationship between knowledge and attitudes in the public understanding of science in Britain'. Public Understanding of Science 4 (1), pp. 57-74. https://doi .org/10.1088/0963-6625/4/1/004.

Evans, J. H. (2011). 'Epistemological and moral conflict between religion and science'. Journal for the Scientific Study of Religion 50 (4), pp. 707-727. https://doi.org/10.1111/j.1468-5906.2011.01603.x.

Finkelstein, J. A., Quaranto, B. R. and Schwartz, C. E. (2014). 'Threats to the internal validity of spinal surgery outcome assessment: recalibration response shift or implicit theories of change?' Applied Research in Quality of Life 9 (2), pp. 215-232. https://doi.org/10.1007/s11482-013-9221-2.

Funk, C. and Kennedy, B. (5th November 2009). How Americans see climate change in 5 charts.

URL: https://www. pewforum.org/2009/11/05/scientists-and-belief/.

Gauchat, G. (2008). 'A test of three theories of anti-science attitudes'. Sociological Focus 41 (4), pp. 337-357. https : //doi .org/10 .1080/00380237.2008.10571338.

- (2011). 'The cultural authority of science: Public trust and acceptance of organized science'. Public Understanding of Science 20 (6), pp. 751-770. https://doi.org/10.1177/0963662510365246.

- (2012). 'Politicization of science in the public sphere: a study of public trust in the United States, 1974 to 2010'. American Sociological Review 77 (2), pp. 167-187. https://doi.org/10.1177/0003122412438225.

Giddens, A. (1991). Modernity and Self-Identity: Self and Society in the Late Modern Age. Stanford, U.S.A.: Stanford University Press.

Gieryn, T. F. (1999). Cultural Boundaries of Science: Credibility on the Line. Chicago, U.S.A.: University of Chicago Press. URL: https://www press . uchica go.edu/ucp/books/book/chicago/C/bo3642202.html.

Goode, G. B. (1889). Museum-history and museums of history. New Rochelle, NY, U.S.A.: Knickerbocker Press. 
Guenther, L. and Ruhrmann, G. (2016). 'Scientific evidence and mass media: investigating the journalistic intention to represent scientific uncertainty'. Public Understanding of Science 25 (8), pp. 927-943. https://doi.org/10.1177/0963662515625479.

Habermas, J. (1989). 'Technology and science as ideology'. In: Jürgen Habermas on society and politics: a reader. Ed. by S. Seidman. Boston, MA, U.S.A.: Beacon Press, pp. 237-265.

Hawley, P. H., Short, S. D., McCune, L. A., Osman, M. R. and Little, T. D. (2011). 'What's the matter with Kansas? The development and confirmation of the evolutionary attitudes and literacy survey (EALS)'. Evolution: Education and Outreach 4 (1), pp. 117-132. https://doi .org/10.1007/s12052-010-0294-1.

Hawley, P. H. and Sinatra, G. M. (2019). 'Declawing the dinosaurs in the science classroom: reducing christian teachers' anxiety and increasing their efficacy for teaching evolution'. Journal of Research in Science Teaching 56 (4), pp. 375-401. https://doi.org/10.1002/tea.21479.

Hayes, B. C. and Tariq, V. N. (2000). 'Gender differences in scientific knowledge and attitudes toward science: a comparative study of four Anglo-American nations'. Public Understanding of Science 9 (4), pp. 433-447. https://doi.org/10.1088/0963-6625/9/4/306.

Johnson, A. L. (2014). 'Math attitudes and interests of adult Science Café participants'. Masters thesis. Seattle, WA, U.S.A.: University of Washington. URL: http: //hdl . handle. net/1773/27128.

Johnson, D., Scheitle, C. and Ecklund, E. (2015). 'Individual religiosity and orientation towards science: reformulating relationships'. Sociological Science 2, pp. 106-124. https://doi.org/10.15195/v2.a7.

Kahan, D. M. (2015). 'Climate-science communication and the measurement problem'. Political Psychology 36, pp. 1-43. https://doi.org/10.1111/pops.12244.

Kahan, D. M., Jenkins-Smith, H. and Braman, D. (2011). 'Cultural cognition of scientific consensus'. Journal of Risk Research 14 (2), pp. 147-174. https://doi.org/10.1080/13669877.2010.511246.

Kiley, J. and Keeter, S. (2015). Ideological self-identification, political values and partisanship. URL: http://www . aapor.org/AAPOR_Main/media/AnnualMeetingPr oceedings/2015/J2-1-Kiley.pdf.

Kuntz, M. (2012). 'The postmodern assault on science'. EMBO reports 13 (10), pp. 885-889. https://doi.org/10.1038/embor.2012.130.

Lamb, T. (2005). 'The retrospective pretest: an imperfect but useful tool'. Evaluation Exchange 11 (2), pp. 18-19.

Lederman, N. G., Abd-El-Khalick, F., Bell, R. L. and Schwartz, R. S. (2002). 'Views of nature of science questionnaire: toward valid and meaningful assessment of learners' conceptions of nature of science'. Journal of Research in Science Teaching 39 (6), pp. 497-521. https://doi.org/10.1002/tea.10034.

Lombrozo, T., Thanukos, A. and Weisberg, M. (2008). 'The importance of understanding the nature of science for accepting evolution'. Evolution: Education and Outreach 1 (3), pp. 290-298. https://doi.org/10.1007/s12052-008-0061-8.

Maniam, S. and Smith, S. (20th March 2017). A wider partisan and ideological gap between younger, older generations.

URL: https://www . pewresearch.org/fact-tank/2017/03/20/a-wider-partis an-and-ideological-gap-between-younger-older-generations/. 
Manning, C., Lin, K., King, M. and Goodman, I. F. (2012). The science festival alliance: creating a sustainable national network of science festivals - year 2 summative evaluation. Cambridge, MA, U.S.A.

Martin, A. J., Durksen, T. L., Williamson, D., Kiss, J. and Ginns, P. (2016). 'The role of a museum-based science education program in promoting content knowledge and science motivation'. Journal of Research in Science Teaching 53 (9), pp. 1364-1384. https: //doi .org/10.1002/tea.21332.

Merton, R. K. (1973). The sociology of science: theoretical and empirical investigations. Ed. by N. W. Storer. Chicago, IL, U.S.A.: University of Chicago Press.

Miller, J. D. (2004). 'Public understanding of, and attitudes toward, scientific research: what we know and what we need to know'. Public Understanding of Science 13 (3), pp. 273-294. https : //doi .org/10.1177/0963662504044908.

Miller, J. D., Scott, E. C. and Okamoto, S. (2006). 'Public acceptance of evolution'. Science 313 (5788), pp. 765-766. https://doi .org/10.1126/science.1126746.

Moore, F. M. (2008). 'Positional identity and science teacher professional development'. Journal of Research in Science Teaching 45 (6), pp. 684-710. https://doi.org/10.1002/tea.20258.

Nadelson, L., Jorcyk, C., Yang, D., Jarratt Smith, M., Matson, S., Cornell, K. and Husting, V. (2014). 'I just don't trust them: the development and validation of an assessment instrument to measure trust in science and scientists'. School Science and Mathematics 114 (2), pp. 76-86. https://doi.org/10.1111/ssm. 12051.

National Academies of Sciences, Engineering and Medicine (2016). Science literacy: concepts, contexts and consequences. Washington, DC, U.S.A.: The National Academies Press.

National Research Council (2012). Education for life and work: developing transferable knowledge and skills for the 21st century. Washington, DC, U.S.A.: The National Academies Press.

National Science Board (2018). Science and technology: public attitudes and understanding. Science \& Engineering Indicators. Alexandria, VA, U.S.A.: National Center for Science and Engineering Statistics (NCSES).

Norton, M. and Nohara, K. (2009). 'Science cafés. Cross-cultural adaptation and educational applications'. JCOM 8 (4), A01. URL: https://jcom. sissa.it/archive/08/04/Jcom0804(2009)A01.

Pekrun, R. and Perry, R. P. (2014). 'Control-value theory of achievement emotions'. In: International handbook of emotions in education. Ed. by R. Pekrun and L. Linnenbrink-Garcia. New York, NY, U.S.A.: Routledge, pp. 120-141. https://doi.org/10.4324/9780203148211.ch7.

Pew Research Center (5th November 2009). Scientists and belief. URL: https://www . pewforum.org/2009/11/05/scientists-and-belief/.

- (2014). Political ideology by state. URL: https://www . pewforum.org/religious-I andscape-study/compare/political-ideology/by/state/.

- (29th January 2015). Public and scientists' views on science and society: an elaboration of the findings in the AAAS member survey. URL: http://www . pewinternet.org/2015/01/29/public-and-scientists-vie ws-on-science-and-society $/ \% 5$ C\#_Chapter_3:_Attitudes.

Rabe, L. (2009). 'The game of science: a grounded theory of the café scientifique experience'. Doctoral dissertation. Minneapolis, MN, U.S.A.: Capella University. 
Schneider, J. (2010). 'Making space for the "nuances of truth": communication and uncertainty at an environmental journalists' workshop'. Science Communication 32 (2), pp. 171-201. https://doi.org/10.1177/1075547009340344.

Shapin, S. (2008). 'The scientist in 2008'. Seed Magazine 19, pp. 58-62.

Shapin, S. and Schaffer, S. (1985). Leviathan and the Air-Pump: Hobbes, Boyle, and the experimental life. Princeton, NJ, U.S.A.: Princeton University Press.

Short, S. D. and Hawley, P. H. (2015). 'The effects of evolution education: examining attitudes toward and knowledge of evolution in college courses'. Evolutionary Psychology 13 (1), pp. 67-88. https: //doi.org/10.1177/147470491501300105.

Sinatra, G. M. and Seyranian, V. (2016). 'Warm change about hot topics: the role of motivation and emotion in attitude and conceptual change about controversial science topics'. In: APA handbook of educational psychology. Ed. by L. Corno and E. Anderman. Washington, DC, U.S.A.: APA publications, pp. 245-256.

Stocking, S. H. and Holstein, L. W. (2009). 'Manufacturing doubt: journalists' roles and the construction of ignorance in a scientific controversy'. Public

Understanding of Science 18 (1), pp. 23-42. https://doi.org/10.1177/0963662507079373.

Suppe, F. (1977). The structure of scientific theories. Chicago, IL, U.S.A.: University of Illinois Press.

Authors

Cara Ocobock is an Assistant Professor of Anthropology at the University of Notre Dame; she was previously at the University at Albany, SUNY. Her research focuses on how humans adapt physiologically and behaviorally to extremes of physical activity and environment. She recently started a field site in northern Finland working with reindeer herders to better understand modern human adaptations to cold climates and the physical demands of herding reindeer. She has organized and participated in countless science outreach efforts, and in her spare time she is an avid powerlifter. E-mail: cocobock@nd.edu.

Patricia H. Hawley is a psychologist and professor in the College of Education at Texas Tech University. Her research has been predominantly addressed the evolution of power asymmetry in human social groups. Most relevant to the present manuscript is her work addressing cognitive change for difficult topics such as evolution (for which she has six publications) and multiculturalism (works in progress). E-mail: Patricia.Hawley@ttu.edu.

\section{How to cite}

Ocobock, C. and Hawley, P. (2020). 'Science on tap: effective public engagement or preaching to the choir?'. JCOM 19 (01), A04. https://doi.org/10.22323/2.19010204. 